\title{
Comparação entre os processos de salga em salmoura e salga mista do curimatã (Prochilodus nigricans) na região Amazônica
}

\section{Comparing process of brine salting and pickle salting of curimatã (Prochilodus nigricans) in the Amazon area}

\author{
Rogério S. de Jesus, ${ }^{\star}$ Eliane Teixeira Mársico, ${ }^{\star \star}$ Gustavo Xavier W. de Souza, ${ }^{\star \star *}$ Edson Lessi, ${ }^{\star}$ Sérgio C. São Clemente ${ }^{\star \star \star \star}$
}

\begin{abstract}
Resumo
O presente estudo objetivou a comparação tecnológica dos processos de salga mista e salga em salmoura visando a obtenção de um produto de boa qualidade higiênico-sanitária e baixo custo de produção para atender às populações de baixa renda. A pesquisa envolveu medição de parâmetros físico-químicos e microbiológicos utilizando como matéria-prima 50 exemplares de curimatá (Prochilodus nigricans), coletados diretamente dos barcos pesqueiros na cidade de Manaus - AM. As amostras, acondicionadas em caixas isotérmicas com gelo, foram encaminhadas à Planta-Piloto de Pescado do Instituto Nacional de Pesquisas da Amazônia (INPA). No músculo do pescado fresco foram medidas as concentrações de umidade (secagem em estufa a $105^{\circ} \mathrm{C}$ ) e de lipídios (método de Soxhlet). Após o processamento da salga por ambos os métodos realizaram-se análises de cloretos, umidade, ranço e contagens microbiológicas para avaliar possível contaminação durante o processo. O teor médio de umidade no pescado fresco foi de $75,89 \%$ e o teor médio de lipídios, de $2,52 \%$. O pescado submetido a salga em salmoura, no 6o dia do processo apresentou absorção de $16,52 \%$ de $\mathrm{NaCl}$ e $53,48 \%$ de umidade. Os exemplares submetidos a salga mista no mesmo período apresentaram valores de $17,31 \%$ de $\mathrm{NaCl}$ e $48,72 \%$ de umidade. Os resultados referentes à pesquisa de ranço foram positivos para todas as amostras submetidas a processo de salga mista e negativos para as amostras submetidas a salga em salmoura. Ficou evidente que o processo de salga mista apresentou vantagens sobre o processo de salga em salmoura com relação aos níveis de $\mathrm{NaCl}$, que foram maiores, e de umidade, que foi menor, ao final de seis dias de processamento. No entanto, os resultados microbiológicos obtidos evidenciam vantagens no processo de salga em salmoura, pois o crescimento de halófilos extremos e moderados foi menor neste tipo de tratamento e a população de bolores e leveduras teve maior crescimento nos produtos submetidos ao processo de salga mista.
\end{abstract}

Palavras-chave: salga em salmoura, salga mista, peixe, pescado salgado.

\begin{abstract}
With the purpose of knowing the stages of the technological process of brine salting and pickle salting to compares through physical-chemistries and microbiological analyses the products submitted to these processes, 50 fishes of the species Prochilodus nigricans (curimatã) were used, obtained directly in fishes ships in the city of Manaus - AM. The samples conditioned in isothermals recipients with ice, were guided to the laboratory of fish products of the National Institute of Research of Amazônia (INPA). After ends of the processing of it salts, the absorption of $\mathrm{NaCl}$ and elimination of water were observed and bacterial contamination were evaluated. In the fresh fish we evaluate the humidity that was $75,89 \%$ and fat that was $2,52 \%$. On the fish salted by the process of brine salting at the end of 6 days presented $16,52 \%$ of $\mathrm{NaCl}$ and $53,48 \%$ of humidity. The fish salted by the pickle salting, at the end of the same time, presented levels of $17,31 \%$ of $\mathrm{NaCl}$ and $48,72 \%$ of humidity.
\end{abstract}

Keywords: brine salting, pickle salting, fish, salted fish.

\section{Introdução}

O peixe apresenta grande importância nutricional para populações de baixa renda na região amazônica. Pensando neste fator, a cada dia buscam-se tecnologias que objetivem meIhor aproveitamento do pescado, pelo fato de ser um alimen- to altamente perecível quando in natura, o que determina um tempo de vida útil curto e possibilidade de contaminação bacteriana que se estende desde a captura até a mesa do consumidor, quando os processos de conservação não são adequados. O curimatã (Prochilodus nigricans) contribui anualmente com cerca de $21 \%$ do pescado comercializado no

\footnotetext{
* Pesquisadores do Instituto Nacional de Pesquisas da Amazônia, Manaus, AM.

** Professora da Faculdade de Veterinária da Universidade do Grande Rio, Silva Jardim, RJ.

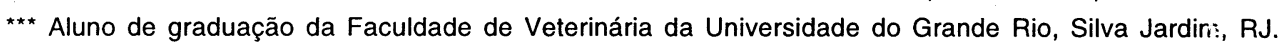

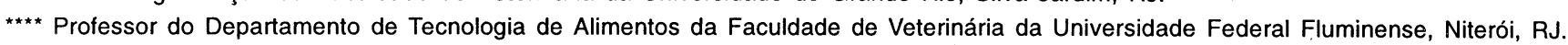


mercado de Manaus, o que justifica a opção pela espécie neste estudo (FEPEAM, 2000).

Tendo em vista o lado econômico e o aumento da vida de prateleira deste produto, procurou-se estabelecer uma tecnologia simplificada de salga que pudesse ser facilmente utilizada pelas populações distantes dos centros urbanos. Dias (1983) cita que embora de fácil aplicação na região amazônica, o processo de salga é totalmente empírico, feito sem técnica e sem critério higiênico-sanitário, tornando impraticável a obtenção de um produto de boa qualidade.

Segundo Stansby e Olcott (1963), um peixe sadio possui um conteúdo de água e gordura cuja soma gira em torno de $80 \%$. Quando um peixe deposita gordura em seus músculos, ela vem substituir uma quantidade equivalente de água e viceversa. Com relação às proteínas, é importante salientar que são susceptíveis a modificações por fatores físicos e químicos resultantes da ação do sal (Borgstrom, 1965).

O processo de salga baseia-se no princípio da desidratação osmótica, onde os tecidos do peixe vivo atuam como membranas semipermeáveis e, após a morte do animal, estas se tornam permeáveis, permitindo a entrada do sal por difusão, à medida que ocorre desidratação dos tecidos (Burgess et al., 1967). Ogawa e Maia (1999) citam que em concentrações de 1 a $3 \%$ de sal, verifica-se uma aceleração no desenvolvimento da maioria das bactérias patogênicas e nãopatogênicas envolvidas no processo de putrefação. Jensen (1954) descreve que o sal tem ação sobre os microrganismos de forma bacteriostática, plasmolítica e bactericida, reduzindo a solubilidade do oxigênio na água, dificultando a aerobiose e a pressão osmótica adversa, inibindo o uso da água pelos microrganismos. Burgess et al. (1967) consideram a salga um processo de preservação baseada na penetração de cloreto de sódio no tecido do pescado, controlada por fatores físicos, químicos e bioquímicos, resultando na alteração dos constituintes musculares, principalmente proteínas, que sofrem desnaturação quando a concentração salina no pescado se aproxima de $9 \%$, descrevendo que o sal comum e em concentrações suficientes, retarda e, às vezes, impede alteração bacteriana do pescado.

No pescado salgado, a oxidação de lipídios é favorecida tendo em vista que além de serem ricos em ácidos graxos polinsaturados, a presença de $\mathrm{NaCl}$ acelera esta reação por ativar as lípases. O processo de rancidez oxidativa ocorre tanto durante a salga como no período de estocagem, com a decomposição de lipídios, ocasionando odor desagradável e offflavours (Cornejo et al., 1997). Para Effemberger e Schotte (1972), se a gordura dos tecidos forem submetidas simultaneamente à luz e ao oxigênio, sofrem alterações oxidativas que se traduzem pela sua rancificação, e como é produzida espontaneamente, é caracterizada como autoxidativa, que é dependente da temperatura, da intensidade e composição da luz, do tempo que dura a ação e da tensão parcial do oxigênio.

O pescado submetido a salga tem uma rápida perda de peso nos primeiros dias do processo, ao redor de $25 \%$ do peso original, seguida de redução gradual até atingir uma perda em torno de 30\% (Cornejo et al., 1997).

A salga em salmoura é um processo onde o pescado é mergulhado em salmoura artificial saturada, com mais de $26,5 \%$ de sal a $25^{\circ} \mathrm{C}$ (Sanchez, 1989). Borgstrom (1965) considera o processo de salga úmida, por meio de salmoura, o mais indicado para peixes gordos, pois os peixes, ficando imersos, não se expõem à oxidação.

A salga mista é uma combinação da salga seca e da salga úmida, onde a água formada pela exsudação não é eliminada, formando uma salmoura natural, que irá submergir o pescado (Botelho e Nort, 1974; Sanchez, 1989; Cornejo et al., 1997).

Huss (1997) descreve que o peixe salgado ou seco pode se deteriorar devido à proliferação de bactérias halófilas ou de bolores e leveduras, que podem ser introduzidos com o sal ou por contaminação de equipamentos ou utensílios mal higienizados.

Este estudo teve por objetivos a comparação tecnológica dos processos de salga em salmoura e mista, visando à obtenção de um produto de boa qualidade higiênico-sanitária para consumo humano e de baixo custo na produção para atender às necessidades econômicas das populações de baixa renda, e verificar o tempo aproximado para que sejam atingidos os níveis de $\mathrm{NaCl}$ e umidade exigidos pela legislação em vigor (Brasil, 1997), bem como o seu tempo de vida útil.

\section{Material e métodos}

Foram adquiridos 50 exemplares de curimatá (Prochilodus nigricans) logo após a captura em um afluente do rio Amazonas, e transportados em caixas isotérmicas entre camadas de gelo para a Planta-Piloto de Pescado do Instituto Nacional de Pesquisas da Amazônia, em Manaus - AM, onde cada exemplar foi medido, pesado e, posteriormente, eviscerado. O peso médio das amostras foi de $0,475 \mathrm{~kg}$, com comprimento standard médio de $28,0 \mathrm{~cm}$.

Os peixes foram divididos em dois lotes de 25 exemplares. Um lote constituído de $11,55 \mathrm{~kg}$ de peixe eviscerado e "ticado" (preparação cabocla que consiste em fazer cortes transversais na musculatura do peixe em espaço de cerca de $1 \mathrm{~mm}$, com a finalidade de cortar as espinhas e facilitar a penetração do sal). Esse lote foi submetido a salga em salmoura a $40 \%$ preparada com 10 litros de água, $2,0 \mathrm{~kg}$ de sal refinado e 2,0kg de sal grosso. Em recipiente plástico de 40 litros, os peixes foram colocados em posição lateral e foi adicionada a salmoura, mantendo-se os peixes submersos com auxílio de tampa de matéria plástica.

O 2 o lote, com peso total de $10,95 \mathrm{~kg}$, foi submetido a processo de salga mista, sendo somente eviscerados e colocados entre camadas de sal (sal grosso e sal fino, na taxa de 1:1) em recipiente de plástico, tipo balde, assegurando-se que a primeira e a última camadas fossem de sal. Sobre as camadas alternadas de sal e pescado, foi colocada uma tampa de matéria plástica, que recebeu o peso utilizado a partir do $2 \underline{0}$ dia de cura para forçar a saída de água do músculo do pescado, mantendo-se ambos os processos por seis dias. Na salga mista, quando a quantidade de água exsudada do pescado, após cinco a seis horas de cura, não é suficiente para cobri-lo, deve ser adicionada quantidade suficiente de salmoura artificial saturada para cobrir o pescado. 
No pescado in natura, mediu-se o teor de umidade em estufa a $105^{\circ} \mathrm{C}$ por gravimetria e o teor de lipídios pelo método de Soxhlet, utilizando éter de petróleo como solvente, seguindo as Normas Analíticas do Instituto Adolfo Lutz (São Paulo, 1985). Durante o processamento da salga, tanto em salmoura como mista, as concentrações de água no músculo foram determinadas, durante seis dias, assim como os teores de cloreto de sódio $(\mathrm{NaCl})$ absorvido e a atividade de água (Aa) do músculo, num medidor da marca Lufft (Alemanha). Sobre o pescado processado, foi realizada a prova de Kreiss, para detectar a rancidez oxidativa, perceptível nos produtos acabados, seguindo a metodologia do LANARA (Brasil, 1981).

As análises microbiológicas realizadas sobre o pescado processado, por salga em salmoura e mista, constaram de contagem de halófilos moderados, halófilos extremos, bolores e leveduras, de acordo com as especificações do ICMSF (1984) e do LANARA (Brasil, 1981).

\section{Resultados e discussão}

Os peixes com peso médio de $0,475 \mathrm{~kg}$ e com $28 \mathrm{~cm}$ de comprimento padrão médio, analisados quanto à concentração de umidade, apresentaram valor médio de $75,90 \%$ no músculo fresco e concentração de gordura de $2,51 \mathrm{~g}$ por $100 \mathrm{~g}$ de músculo. Durante os processos de salga, os lotes submetidos à salga em salmoura e à salga mista, durante seis dias, foram analisados e os resultados estão apresentados na Tabela 1.

Tabela 1 - Concentrações de umidade, de absorção de cloreto de sódio e de atividade de água ( $\mathrm{Aa}$ ) no músculo de Prochilodus nigricans durante seis dias de salga, em Manaus (AM)

\begin{tabular}{c|c|c|cc|c|c}
\hline \multirow{2}{*}{ Dias de Salga } & \multicolumn{2}{|c|}{$\begin{array}{c}\text { Umidade } \\
(\mathrm{g} / 100 \mathrm{~g})\end{array}$} & \multicolumn{2}{c|}{$\begin{array}{c}\text { NaCl absorvido } \\
(\mathrm{g} / 100 \mathrm{~g})\end{array}$} & \multicolumn{2}{c}{ Aa } \\
\cline { 2 - 7 } & Salmoura & Mista & Salmoura & Mista & Salmoura & Mista \\
\hline 1 & 64,0 & 61,0 & 8,9 & 9,0 & 0,90 & 0,89 \\
\hline 2 & 61,0 & 55,0 & 11,0 & 15,0 & 0,86 & 0,86 \\
\hline 5 & 57,0 & 50,0 & 16,0 & 17,0 & 0,79 & 0,75 \\
\hline 6 & 53,0 & 49,0 & 17,0 & 17,0 & 0,78 & 0,75 \\
\hline
\end{tabular}

Os valores das concentrações de cloreto de sódio absorvido pelo músculo do pescado, assim como os teores de umida-

Tabela 2 - Contagens (UFC/g) de halófilos moderados, halófilos extremos e bolores e leveduras nos produtos de pescado obtidos por salga em salmoura e mista.

\begin{tabular}{c|c|c|c}
\hline $\begin{array}{c}\text { Tipo de } \\
\text { Processamento }\end{array}$ & $\begin{array}{c}\text { Halófilos moderados } \\
\left(28^{\circ} \mathrm{C} / 4-5 \text { dias }\right)\end{array}$ & $\begin{array}{c}\text { Halófilos extremos } \\
\left(35^{\circ} \mathrm{C} / 7-10 \mathrm{dias}\right)\end{array}$ & $\begin{array}{c}\text { Bolores e Leveduras } \\
\text { (UFC/g) }\end{array}$ \\
\hline Salga em salmoura & $1,6 \times 10^{2}$ & $6,3 \times 10^{2}$ & $1,8 \times 10^{2}$ \\
\hline Salga mista & $1,1 \times 10^{4}$ & $2,6 \times 10^{3}$ & $4,2 \times 10^{3}$ \\
\hline
\end{tabular}

dos, halófilos extremos, bolores e leveduras estão apresentados na Tabela 2.

de nos dois tipos de salga foram considerados satisfatórios, (1985), que processaram sardinhas, Sardinella brasiliensis, por salga em salmoura, em Niterói (RJ). Resultados semehantes também foram obtidos por Silva e Lessi (2001), traManaus (AM).

Os resultados da determinação do Índice de Kreiss, para detectar o cheiro e odor de ranço nas amostras de músculo salgado de Prochilodus nigricans, foram "positivos" para todas as amostras submetidas à salga mista e "negativos" para aquelas submetidas a salga em salmoura, tanto durando, considerando que a salmoura isola o peixe salgado do ar atmosférico, rico em oxigênio, que é iniciador da oxidação lipídica.

Lessi (2001) realizaram análise sensorial para detectar odor e sabor de ranço nas amostras de cubiu, Anodus elongatus, salgado em salmoura durante 12 dias, acondicionado em pratos de poliestireno, embalado com filme de polietileno e resfriado em geladeira a $10 \pm 2^{\circ} \mathrm{C}$, avaliando as alterações da qualidade e somente na $9^{\text {a }}$ semana de estocagem foi que apareceram sinais de ranço. Portanto, o biu foi considerado apto para consumo durante oito sema位ôes de estocagem. Os autores consideraram adequado o tempo de estocagem para peixe salgado em salmoura e resfriado.

As sardinhas salgadas em salmoura por Rodrigues e Lessi (1985), estocadas em baldes de polietileno e acondicionadas à temperatura de $30 \pm 3^{\circ} \mathrm{C}$, mantiveram-se em condições de consumo durante cinco semanas, sendo que o crescimento de fungos foi o fator limitante. Quando o produto foi mantido em geladeira a $15 \pm 2^{\circ} \mathrm{C}$, o tempo de vida útil foi de sete semanas, sendo que o aparecimento de odor e sabor de ranço foi o fator limitante.

A determinação da presença e contagem de halófilos modera-

Os resultados microbiológicos obtidos evidenciam vantagens no processo de salga em salmoura, pois o crescimento de halófilos extremos e moderados foi menor neste tipo de tratamento. Ademais, a população de bolores e leveduras teve maior crescimento nos produtos submetidos a processo de salga mista. coincidindo com os resultados obtidos por Rodrigues e Lessi 


\section{Conclusões}

A salga em salmoura do curimatá, Prochilodus nigricans, nas condições experimentais utilizadas foi mais eficiente porque

\section{Referências}

BORGSTROM, G. Fish as Food. Vol. III, New York and London: Academic Press, 1965.

BOTELHO, A.T. e NORT, E. Pescado salgado no Brasil. FAO/SUDEPE. Série Doc. Tec., n. 6, 40 p. 1974.

BRASIL. Ministério da Agricultura. Secretaria Nacional de Defesa Agropecuária. Laboratório Nacional de Referência Animal (LANARA). Métodos Analíticos Oficiais para Controle de Produtos de Origem Animal e seus Ingredientes. II-Métodos Físicos e Químicos. Brasília, DF, 1981.

BRASIL. Ministério da Agricultura.Regulamento da Inspeção Industrial e Sanitária de Produtos de Origem Animal - RIISPOA. Aprovado pelo Decreto $n^{\circ} 30.691$, de 29/3/52, alterado pelos Decretos $n^{\circ s} 1.255$ de 25/6/62, 1236 de 2/9/94, 1.812, de 8/2/96 e 2.244 de 4/6/97, Brasília, DF, 1997.

BURGESS, G.H.O.; CUTTING, C.L.; LOVERN, J.A.; WATERMAN, J.J. Fish Handling \& Processing. New York: Chemical Publishing Co. Inc., 1967.

CORNEJO, F.E.P.; NOGUEIRA, N.I. e PARK, K.J. Manual de preserva̧̧ão do pescado salgado-seco. EMBRAPA, 1997.

DIAS, A.F. Salga e secagem do pirarucu (Arapaima gigas) - CUVIER, 1829, com aplicação de coletores solares. 1983. 150 p. Dissertação (Mestrado)-INPAFUA

EFFEMBERGUER, G. e SCHOTTE, K. Empaquetado de la carne y productos cárnicos. Zaragoza, España: Editorial Acribia, 1972. a salmoura isolou o peixe salgado do oxigênio do ar, impedindo a oxidação lipídica, estendendo, conseqüentemente, a vida útil do pescado salgado.

FEPEAM - Federação dos Pescadores dos Estados do Amazonas e Roraima. Perfil econômico do setor pesqueiro do estado do Amazonas. Manaus, AM, Jan. 2000. $15 \mathrm{p}$.

HUSS, H.H. Garantia da qualidade dos produtos da pesca. Departamento de Investigação dos Produtos da Pesca. Ministério da Agricultura e da Pesca, Dinamarca - FAO, 1997.

ICMSF. Microrganismos de los alimentos. Técnicas de Análisis Microbiológico. Zaragoza, España: Editorial Acribia, 1984. 431 p.

JENSEN, B. Microbiology of Meats. Illinois: Garrard Press, 1954.

OGAWA, M. e MAIA, E.L. Manual de Pesca. Ciência e Tecnologia do Pescado. Livraria Varela, 1999.

RODRIGUES, M.C.R.E. e LESSI, E. Processamento de sardinha, Sardinella brasiliensis, por salga em salmoura. Revista Brasil. de Farmácia, Rio de Janeiro, p. 92-102, 1985.

SANCHES, L. Pescado: matéria-prima e processamento. Fundação Cargil, 1989.

SÃO PAULO. Instituto Adolfo Lutz, Normas Analíticas. In: Métodos químicos e físicos para análises de alimento. Ed. $3^{\circ}$ v.1. São Paulo: Governo de São Paulo, 1985.

SILVA, K.Y. e LESSI, E. Salga úmida do cubiu, Anodus elongatus (Agassiz, 1829). JORNADA DE INICIAÇÃO CIENTÍFICA DOPIBIC/INPA. INPA, 10., 2001, Manaus. Anais..

STANSBY, M. e OLCOTT, H.S. Composition of fish industrial. New York: Fish Technology (Stansby), 1963. 